\title{
Portable Gas Analyzer Based on Fourier Transform Infrared Spectrometer for Patrolling and Examining Gas Exhaust
}

\author{
Yuntao Liang, ${ }^{1}$ Xiaojun Tang, ${ }^{2}$ Xuliang Zhang, ${ }^{2}$ Fuchao Tian, ${ }^{1,3}$ \\ Yong Sun, ${ }^{1}$ and Haozhe Dong ${ }^{4}$ \\ ${ }^{1}$ State Key Laboratory of Coal Safety, China Coal Research Institute, Shenyang Branch, Shenyang 110016, China \\ ${ }^{2}$ State Key Laboratory of Electrical Insulation \& Power Equipment, Xian Jiaotong University, Xian 710049, China \\ ${ }^{3}$ School of Safety Engineering, China University of Mining and Technology, Xuzhou 221008, China \\ ${ }^{4}$ Shenzhen Yetongda LtC, Shenzhen 518034, China
}

Correspondence should be addressed to Xiaojun Tang; xiaojun_tang@mail.xjtu.edu.cn

Received 6 November 2015; Accepted 14 December 2015

Academic Editor: Eugen Culea

Copyright (c) 2015 Yuntao Liang et al. This is an open access article distributed under the Creative Commons Attribution License, which permits unrestricted use, distribution, and reproduction in any medium, provided the original work is properly cited.

\begin{abstract}
Aimed at monitoring emission of organic gases such as $\mathrm{CH}_{4}, \mathrm{C}_{2} \mathrm{H}_{6}, \mathrm{C}_{3} \mathrm{H}_{8}$, iso- $\mathrm{C}_{4} \mathrm{H}_{10}, \mathrm{n}-\mathrm{C}_{4} \mathrm{H}_{10}, \mathrm{C}_{2} \mathrm{H}_{4}, \mathrm{C}_{3} \mathrm{H}_{6}, \mathrm{C}_{2} \mathrm{H}_{2}, \mathrm{CO}$, and $\mathrm{CO}_{2}$, from coal mines, petroleum refineries, and other plants, a Fourier Transform Infrared (FT-IR) spectrometer was used to develop a portable gas analyzer for patrolling and examining gas exhaust. Firstly, structure of the instrument was introduced. Then, a spectral analysis approach was presented. Finally, instrument was tested with standard gases and with actual gases emitted from a petroleum refinery. For the latter test, a gas chromatograph (GC) was used as a reference instrument. The test results showed that the detection limit of every component of analyte was less than $10 \times 10^{-6}$. The maximum test error of every analyte was less than $15 \times 10^{-6}$ when its practical concentration was no more than $500 \times 10^{-6}$. A final comparison showed that the result curves of analytes obtained with FT-IR spectrometer almost overlapped with those obtained with GC, and their resulting noise was less than $6.4 \%$ when the practical gas concentration was above $100 \times 10^{-6}$. As a result, our instrument was suitable to be used as a portable instrument for monitoring exhaust gases.
\end{abstract}

\section{Introduction}

In the past decades, atmospheric pollution in urban areas, especially in many developing countries around the world [1], is a major concern for environmental protection. In recent years, greenhouse gases, including $\mathrm{CO}_{2}, \mathrm{~N}_{2} \mathrm{O}, \mathrm{NO}$, $\mathrm{NO}_{2}, \mathrm{CH}_{4}, \mathrm{NH}_{3}$, and even $\mathrm{CO}$, are of increasing concern because of their potential impact on climate change. As a result, some standards have recently been implemented [2]. In fact, besides these component gases, there may be other components in the exhaust emitted from petroleum refineries, coal mines, and other plants and even in those volatilized from contaminated soil [3-5]. For instance, in the gas mixture emitted from coal mines, there are more than ten components. $\mathrm{C}_{2} \mathrm{H}_{6}, \mathrm{C}_{3} \mathrm{H}_{8}$, iso- $\mathrm{C}_{4} \mathrm{H}_{10}, \mathrm{n}-\mathrm{C}_{4} \mathrm{H}_{10}, \mathrm{C}_{2} \mathrm{H}_{4}$, $\mathrm{C}_{3} \mathrm{H}_{6}$, and $\mathrm{C}_{2} \mathrm{H}_{2}$ also exist besides $\mathrm{CH}_{4}, \mathrm{CO}_{2}$, and $\mathrm{CO}$ [5]. These gases not only bring pollution to the atmosphere but also may be ignited and cause catastrophic disasters. In developing countries with power resources such as coal, petroleum, and so on, there are always many factories that emit such waste gases secretly to reduce production costs. In order to prevent such gases from being emitted continuously, governments of some countries patrol these plants. So it is necessary to develop portable instruments to analyze these areas quantitatively for a patroller.

Although there are many types of sensors [6] and instruments used for gas detection or gas mixture analysis, infrared spectroscopy, mass spectroscopy (MS), and gas chromatography (GC) are still the most common techniques used to analyze multicomponent gas mixtures with high accuracy [7-10]. While both MS and GC provide only ex situ information of analyses, infrared spectroscopy can provide in situ information [8]. Additionally, there are several potential benefits to analyzing gas mixtures with optical analyzers, 
including faster analysis and update rate, no required carriers gas, and maintenance-free operation. Additionally, some types of FT-IR spectrometers, such as Spectrum Two made by Perkin Elmer and Alpha made by Bruker, are portable. This makes it possible to develop portable-type gas analyzers for operators in environmental or safety administrations to patrol and ensure compliance to emissions regulations.

In fact, we have even tried to analyze the above ten components of gas with the FT-IR spectrometer in the laboratory [11]. The testing results showed that the detection limit of all the components was less than $2 \times 10^{-6}$ when the light path is $10 \mathrm{~cm}$ and the spectrum revolution was $1 \mathrm{~cm}^{-1}$. It was not, however, suitable for patrolling gas emissions because the time to complete one analysis was excessive. For many patrollers, the expectation for a single analysis is less than 15 seconds. Therefore, some additional measures must be taken to meet this requirement.

In this paper, we aimed to develop a fast and portabletype multifunctional gases analyzer on the basis of our previous works using FT-IR spectrometer to monitor the gas mixture emitted from coal mines, oil refineries, and other plants. For the monitored gas mixture, ten components were taken as analytes: $\mathrm{CH}_{4}, \mathrm{C}_{2} \mathrm{H}_{6}, \mathrm{C}_{3} \mathrm{H}_{8}$, iso- $\mathrm{C}_{4} \mathrm{H}_{10}, \mathrm{n}-\mathrm{C}_{4} \mathrm{H}_{10}$, $\mathrm{C}_{2} \mathrm{H}_{4}, \mathrm{C}_{3} \mathrm{H}_{6}, \mathrm{C}_{2} \mathrm{H}_{2}, \mathrm{CO}$, and $\mathrm{CO}_{2}$. The structure of the analyzer and techniques used for the gas mixture analysis were introduced at first. Next, both a portable gas analysis instrument developed with an FT-IR spectrometer and GC were used to monitor the gas mixtures emitted from an oil refinery at the same time to illustrate the performance of our instrument. The monitoring results showed that the result curves of FT-IR spectrometer almost overlapped with those of GC. Because GC is accepted as a standard instrument for gas analysis, it can be shown that the monitor results of the FT-IR spectrometer were accurate through the overlapping result curves.

\section{Experiment}

2.1. Instrument Structure. The schematic diagram of the portable gas analyzer based on FT-IR spectrometer is shown in Figure 1. And its physical photo is shown in Figure 2. The gross weight of the instrument was less than $25 \mathrm{~kg}$. It was made with a storage cell, micro-personal computer (MPC), FT-IR spectrometer, temperature sensor, pressure sensor, and gas pump. The storage cell provided power for the FT-IR spectrometer, gas pump, and MPC. The gas pump was used to pump the analyzed gas into gas cell. The temperature sensor and pressure sensor were used to measure the gas temperature and pressure in gas cell for compensating the effects brought to the gas concentration when the instrument was used to analyze sample. In this way, the weight of thermostat and pressostat used in our previous work [11] can be reduced to keep the instrument as portable as possible. MPC read the absorption spectrum of analyte and performed spectrum analysis.

The type of FT-IR spectrometer was the Spectrum Two, a portable-type FT-IR spectrometer developed and produced by Perkin Elmer. Its detector type was DTGS. The optical path was $10 \mathrm{~cm}$. A Norton-Beer medium function was chosen as

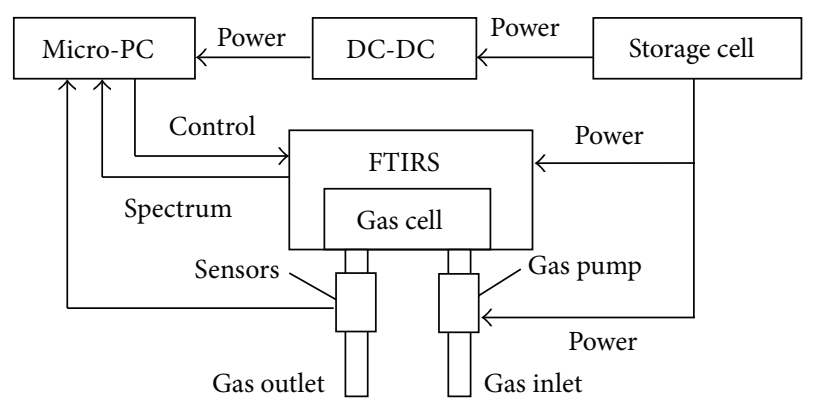

FIGURE 1: Schematic diagram of the portable gas analyzer based on an FT-IR spectrometer. The storage cell provides power for FT-IR spectrometer, gas pump, and micro-PC. The gas pump is used to pump the analyzed gas into gas cell. Sensors include temperature and pressure. They are used to monitor the temperature and pressure of analytes for compensating the effects of gas temperature and pressure on gas concentration. A micro-PC reads the absorption spectrum of analyte and performs the spectrum analysis.

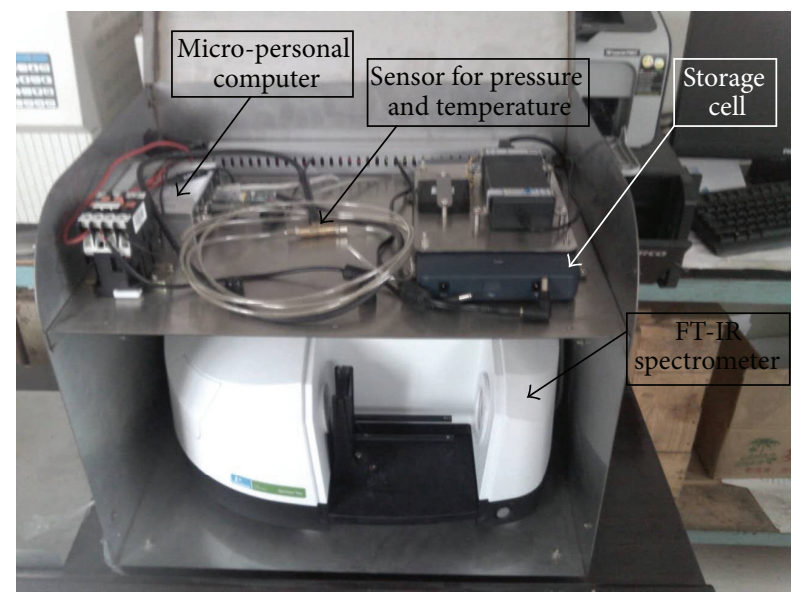

Figure 2: Photo of the portable gas analyzer.

the apodization function since it can provide the best fitting adherence to Beer's law for the spectra measured at moderate resolution during the process of scanning the spectra of gas samples [12]. For the spectrum resolution, $4 \mathrm{~cm}^{-1}$ was chosen to make sure that a complete absorption spectrum could be gotten in less than 15 seconds because analysis speed was also required for patrolling gas emissions while the admissible error could be reduced to $10 \times 10^{-6}$.

The type of the sensor used to measure pressure and temperature was BMP085 produced by Bocsh. The storage cell was also produced by Perkin Elmer. It was bought as an accessory of Spectrum Two.

2.2. Instrument Calibration. The calibration process was the same as that performed in our previous work [11]. For this, 200 sets of samples were used to calibrate the instrument. Among these samples, 30 sets were standard gases, and the others were prepared with standard gases using a gas blending system. The concentration range of every component of analyte was shown in Table 1. Differing from our previous work [11], the range of $\mathrm{CH}_{4}$ increased from $20 \%$ to $100 \%$, that 
TABLE 1: Concentration range of every component of analyte (percent by volume).

\begin{tabular}{lcc}
\hline Item & $\mathrm{Gas}$ & Range \\
\hline 1 & $\mathrm{CH}_{4}$ & $0 \sim 100 \%$ \\
2 & $\mathrm{C}_{2} \mathrm{H}_{6}$ & $0 \sim 2 \%$ \\
3 & $\mathrm{C}_{3} \mathrm{H}_{8}$ & $0 \sim 1 \%$ \\
4 & $\mathrm{iso} \mathrm{C}_{4} \mathrm{H}_{10}$ & $0 \sim 0.5 \%$ \\
5 & ${\mathrm{n}-\mathrm{C}_{4} \mathrm{H}_{10}}_{0 \sim 0.5 \%}$ \\
6 & $\mathrm{C}_{2} \mathrm{H}_{4}$ & $0 \sim 0.5 \%$ \\
7 & $\mathrm{C}_{3} \mathrm{H}_{6}$ & $0 \sim 0.3 \%$ \\
8 & $\mathrm{C}_{2} \mathrm{H}_{2}$ & $0 \sim 0.3 \%$ \\
9 & $\mathrm{CO}_{2}$ & $0 \sim 0.3 \%$ \\
10 & $\mathrm{CO}_{2}$ & $0 \sim 20 \%$ \\
\hline
\end{tabular}

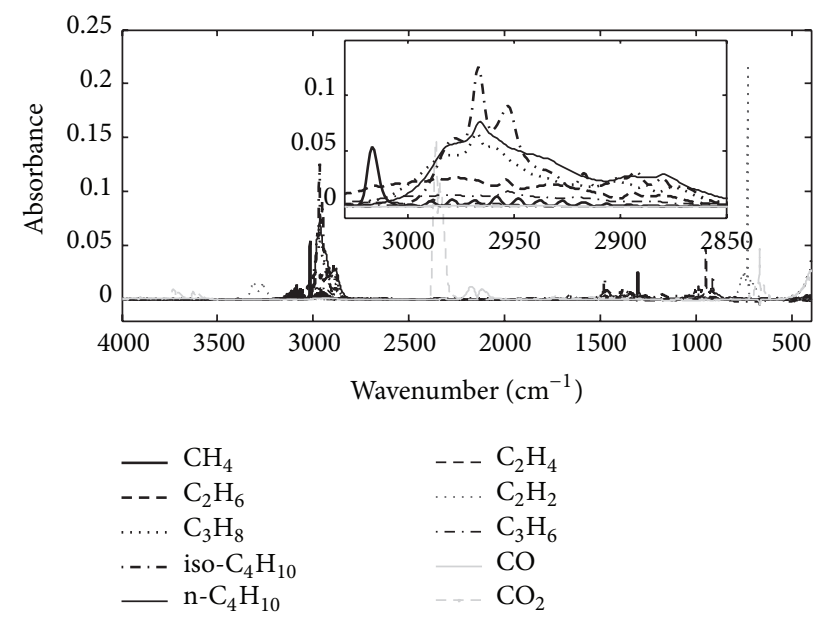

FIGURE 3: Absorption spectra of analytes with concentration of $1000 \mathrm{ppm}$.

of $\mathrm{C}_{2} \mathrm{H}_{6}$ from $1 \%$ to $2 \%$, and that of $\mathrm{C}_{3} \mathrm{H}_{8}$ from $0.5 \%$ to $1 \%$ to meet the need of monitoring natural gas emission. The temperature and pressure of samples were kept as $20^{\circ} \mathrm{C}$ and 760 Torr, respectively, when the calibration sample spectrum was scanned. The gas-flow rate of the gas mixture flowing through the gas cell was kept as $1 \mathrm{~L} / \mathrm{min}$. The absorption spectra of ten components of analyte with concentration of 1000 ppm were shown in Figure 3.

After the spectra of samples had been obtained, their baselines were corrected at first using the method called as The Piecewise Two-Point Autolinear Correlated Correction Method presented by us [13]. Next, the feature variable of every component of analyte was extracted with Tikhonov and Forward Selection according to its concentration and absorptivity [14]. As shown in Figure 3, for the components such as $\mathrm{C}_{2} \mathrm{H}_{2}, \mathrm{C}_{2} \mathrm{H}_{4}, \mathrm{C}_{3} \mathrm{H}_{6}, \mathrm{CO}$, and $\mathrm{CO}_{2}$, whose absorption peaks have good selectivity, Forward Selection was used. For the others, Tikhonov was used because their absorption peaks overlap with others extensively. For $\mathrm{CH}_{4}$, when its concentration range was large, some absorbances of its spectrum were high and close to saturation and more than two feature variables were extracted. One was used for low concentration; the other was used for high concentration.
For the components whose feature variables have good linearity with gas concentration, a multi-input linear analysis model was used. For the components whose feature variables have good selectivity, a polynomial model was used. For the others, Artificial Neural Network (ANN) was used since it has the potential to obtain high accuracy compared with Partial Least Square (PLS) [15]. The calibration approaches were the same as used in our previous work [11].

For quantitative analysis of gas mixture, interferents must be taken into account. In oil gas emitted from oil refinery, there are water vapor and hydrogen, no BTX (benzene, toluene, and xylene), except analytes listed above in the analyzed gas mixture. For water vapor, as discussed in our previous work [11], it was easy to avoid the interference brought from it to every component of the analyte because there was at least one absorption peak that does not overlap with the absorption regions of vapor. Hydrogen is nonpolar molecule and has no absorption peak in spectrum. So it did not bring effect to the analysis of analyte.

2.3. Testing Experiment. In order to illustrate its performance, our instrument was tested with standard gas and then was tested in situ. During the process of testing, differing from the calibration experiment, temperature and pressure of the analyzed gas mixture were not kept as constant but measured and used to compensate for the effects from the change of temperature and pressure to the analysis results. At first, the absorption spectrum was scanned with the FT-IR spectrometer. Then the baseline was recognized and corrected. If both the variances of ten absorbances near $3500 \mathrm{~cm}^{-1}$ and that near $2500 \mathrm{~cm}^{-1}$ were less than 0.01 , the baseline was corrected according to [13]. Otherwise, the gas cell was cleaned with nitrogen and the background spectrum was scanned again to avoid the effect of environment parameters such as temperature to the absorption spectrum. After the corrected spectrum was analyzed with the analysis models calibrated in Section 2.2, the analysis results were compensated as

$$
c_{c i}=\frac{c_{i} \times 760 \times(T+273)}{293 \times P},
$$

where $P$ is the gas pressure in torr; $T$ is the gas temperature in ${ }^{\circ} \mathrm{C} ; c_{i}$ denotes the concentration of the $i$ th component of analyte obtained directly with the analysis models, while $c_{c i}$ is the compensated result of $c_{i}$. The units of $c_{i}$ and $c_{c i}$ are percent by volume.

For the test in situ, GC analyzer was used as a reference instrument to analyze the same gas mixture analyzed with FTIR spectrometer ex situ. The diameter of the silica capillary column used in the GC is $2 \mathrm{~mm}$, and its length was $4 \mathrm{~m}$. Nitrogen was taken as the carrier gas. The flow rate was $30 \mathrm{~mL} / \mathrm{min}$. Both the injector and detector temperature were $60^{\circ} \mathrm{C}$. The FT-IR spectrometer was placed in a petroleum refinery. Next, the GC analyzer was placed outside of the petroleum refinery for the purpose of safety because it had a hydrogen flame ionization detector. When the concentration of organic gas around the GC analyzer was high, organic gas may be ignited by hydrogen flame; ignition was possible. 
TABLE 2: Mean square root of the analyte and maximum analysis error in case of background spectra.

\begin{tabular}{lccc}
\hline Item & $\mathrm{Gas}$ & Mean square root & Maximum error \\
\hline 1 & $\mathrm{CH}_{4}$ & $3.3 \times 10^{-6}$ & $5.9 \times 10^{-6}$ \\
2 & $\mathrm{C}_{2} \mathrm{H}_{6}$ & $5.4 \times 10^{-6}$ & $7.7 \times 10^{-6}$ \\
3 & $\mathrm{C}_{3} \mathrm{H}_{8}$ & $6.5 \times 10^{-6}$ & $8.7 \times 10^{-6}$ \\
4 & $\mathrm{iso}^{-} \mathrm{C}_{4} \mathrm{H}_{10}$ & $3.2 \times 10^{-6}$ & $6.9 \times 10^{-6}$ \\
5 & ${\mathrm{n}-\mathrm{C}_{4} \mathrm{H}_{10}}^{\mathrm{C}_{2} \mathrm{H}_{4}}$ & $6.8 \times 10^{-6}$ & $9.2 \times 10^{-6}$ \\
6 & $2.6 \times 10^{-6}$ & $6.1 \times 10^{-6}$ \\
7 & $\mathrm{C}_{3} \mathrm{H}_{6}$ & $4.0 \times 10^{-6}$ & $8.1 \times 10^{-6}$ \\
8 & $\mathrm{C}_{2} \mathrm{H}_{2}$ & $1.2 \times 10^{-6}$ & $2.5 \times 10^{-6}$ \\
9 & $\mathrm{CO}_{10}$ & $4.6 \times 10^{-6}$ & $7.9 \times 10^{-6}$ \\
10 & $\mathrm{CO}_{2}$ & $2.9 \times 10^{-6}$ & $6.0 \times 10^{-6}$ \\
\hline
\end{tabular}

Normally, the concentration of organic gas in petroleum refineries is also low. In order to test the performance of our instrument over larger ranges, a gas leakage was caused purposely. The leakage gas was pumped into the gas cell of the FT-IR spectrometer and then was imported into GC analyzer with a connecting pipe.

\section{Results and Analysis}

\subsection{Results Tested with Standard Gas}

3.1.1. Detection Limits. Detection limit is an important index for patrol instruments. In many cases of atmospheric environmental monitoring, the concentration of analyte is low, and every absorbance of the absorption spectrum of the analyzed gas mixture is close to zero. Because every absorbance at different wavenumbers has almost constant noise levels when its value is close to zero, in this work, the detection limit was determined directly with the background spectra. First, nitrogen was taken as the background gas and was scanned continuously for 30 repetitions. Then, these ground spectra were analyzed with the calibration models developed in Section 2. Finally, both the standard deviation (rootmean-square error, RMS error) and maximum error of every component were calculated and listed in Table 2. From this table, it could be found that the maximum error of every component was less than $10 \times 10^{-6}$. Because the permitted concentration limit of $\mathrm{CO}$ for long time-work is $24 \times 10^{-6}$ and that of total alkane is $80 \mathrm{mg} / \mathrm{m}^{3}$ (around $31 \times 10^{-6}$ for $\mathrm{C}_{4} \mathrm{H}_{10}$ ) in China [16], it was acceptable if the maximum testing error list in Table 2 was taken as detection limit of the portable gas analyzer. By comparing Table 2 with our previous work [11] where the maximum analysis error in the case of background spectra was less than $2 \times 10^{-6}$, it could be found that the detection limit has been raised from $2 \times 10^{-6}$ to $10 \times 10^{-6}$ because of the decreasing spectrum resolution of scanning times.

3.1.2. Results Tested with Gas Mixture. The portable gas analyzer developed in this work was also tested with the gas mixture. The test samples were the same as those used in our previous work [11]. The practical concentrations of every component of the analyte covered its range. The analyzed results of the fifteen testing samples were shown in Table 3 . In Table 3, Exp means the practical concentrations of every component of the gas while Anal means the analyzed results. The maximum testing error or maximum relative error was listed in Table 4 as gas concentration rise from 0 to $100 \%$.

From Table 4, it could be shown that the relative error decreased from $9.5 \%$ to $2.2 \%$ when gas concentration rose from $100 \times 10^{-6}$ to $100 \%$. When the gas concentration was no more than $10 \times 10^{-6}$, the maximum error was $9.3 \times 10^{-6}$. It was the test error of $\mathrm{n}-\mathrm{C}_{4} \mathrm{H}_{10}$ in the second test sample. Compared with Table 2, it was found that it was a little greater than the maximum error of $\mathrm{n}-\mathrm{C}_{4} \mathrm{H}_{10}$, which is $9.2 \times 10^{-6}$. This was due to the effect of methane and ethane because of extensively overlapped absorption spectra. Certainly, the error was still less than detection limit.

From Table 3, it could also be shown that the analyzed results of $\mathrm{C}_{2} \mathrm{H}_{4}, \mathrm{C}_{3} \mathrm{H}_{6}, \mathrm{C}_{2} \mathrm{H}_{2}, \mathrm{CO}_{2}$, and $\mathrm{CO}$ had relatively higher accuracy. For instance, among these five components when their practical concentrations were less than $10 \times 10^{-6}$, $\mathrm{C}_{3} \mathrm{H}_{6}$ had a maximum error of $4.8 \times 10^{-6}$, which appeared in the 12th sample. As discussed in our previous work [11], this was due to their absorption peaks having good selectivity.

3.2. Test Results In Situ. In order to validate the performance of our gas analyzer, a test in situ and online was also performed together with GC. Both the test results of the FTIR spectrometer and GC were shown in Figure 4. In this figure, curves denoted as "FT-IR" mean it was calculated with spectra from the FT-IR spectrometer. Curves denoted as "GC" mean they were derived with GC. The test time was chosen from 5 A.M. to 9 A.M. because the ambient temperature changes greatly during this period of time. Because the length of the pipe linking FT-IR spectrometer and GC analyzer was greater than 30 meters, the change of gas concentration at the location of the GC analyzer lagged behind that of FT-IR spectrometer. For the simplicity of comparison, the result curves of GC analyzer had been moved to left side to make the peaks of concentrations appear at the same time. Additionally, to save space, testing results of $\mathrm{C}_{2} \mathrm{H}_{4}$, $\mathrm{C}_{3} \mathrm{H}_{6}, \mathrm{C}_{2} \mathrm{H}_{2}, \mathrm{CO}_{2}$, and $\mathrm{CO}$ were not shown here since they had relatively higher accuracy and the others were enough to demonstrate the performance of our instrument.

From Figure 4, it was easy to find that, for alkane gas monitoring, FT-IR almost overlaps with GC. This indicated that the development scheme presented in this paper was suitable. Both the calibration approach and the compensation method of temperature and pressure were included. Consequently, the portable gas analyzer could be adopted for use.

Certainly, there were also some difference between the two systems. First, the difference between FT-IR and GC was high at times. For instance, in Figure 4(e), FT-IR was $490 \times 10^{-6}$ when GC was $380 \times 10^{-6}$, and the maximum testing difference of n-butane reached $110 \times 10^{-6}$. The relative error was $29 \%$, much higher than $9.5 \%$, the maximum test relative error with gas samples when the concentration range was from $100 \times 10^{-6}$ to $1000 \times 10^{-6}$. This might be due to interferents such as n-pentane in the testing in situ. Because 
TABLE 3: Testing results with standard gas mixture.

\begin{tabular}{|c|c|c|c|c|c|c|c|c|c|c|c|}
\hline \multirow{2}{*}{ Item } & & \multicolumn{10}{|c|}{ Concentration of analyte $/ \varphi(\cdot) \times 10^{-6}$} \\
\hline & & $\mathrm{CH}_{4}$ & $\mathrm{C}_{2} \mathrm{H}_{6}$ & $\mathrm{C}_{3} \mathrm{H}_{8}$ & iso- $\mathrm{C}_{4} \mathrm{H}_{10}$ & $\mathrm{n}-\mathrm{C}_{4} \mathrm{H}_{10}$ & $\mathrm{C}_{2} \mathrm{H}_{4}$ & $\mathrm{C}_{3} \mathrm{H}_{6}$ & $\mathrm{C}_{2} \mathrm{H}_{2}$ & $\mathrm{CO}$ & $\mathrm{CO}_{2}$ \\
\hline \multirow{2}{*}{1} & Exp & 976 & 19.8 & 0 & 0 & 0 & 0 & 0 & 0 & 0 & 760 \\
\hline & Anal & 989 & 18.7 & 5.2 & 4.5 & 2.2 & 0 & 1.3 & 0.9 & 1.8 & 786 \\
\hline \multirow{2}{*}{2} & Exp & 99972 & 998 & 199 & 0 & $\mathbf{0}$ & 0 & 0 & 0 & 0 & 0 \\
\hline & Anal & 98823 & 1021 & 212 & 2.1 & 9.3 & 1.8 & 3.4 & 1.1 & 3.6 & 2.1 \\
\hline \multirow{2}{*}{3} & Exp & 99819 & 498 & 199 & 50.0 & 50.0 & 50.0 & 50.0 & 50.0 & 10.0 & 230 \\
\hline & Anal & 101300 & 475 & 217 & 44.3 & 56.6 & 44.6 & 55.3 & 48.8 & 9.8 & 221 \\
\hline \multirow{2}{*}{4} & Exp & 19988 & 498 & 199 & 100 & 100 & 498 & 200 & 50.4 & 15.0 & 1010 \\
\hline & Anal & 20180 & 483 & 218 & 94.6 & 80.1 & 465 & 214 & 46.3 & 15.3 & 1034 \\
\hline \multirow{2}{*}{5} & Exp & 199790 & 9996 & 2987 & 2993 & 2497 & 2989 & 998 & 999 & 600 & 10020 \\
\hline & Anal & 201420 & 10251 & 3129 & 3043 & 2613 & 2823 & 1145 & 1002 & 623 & 10132 \\
\hline \multirow{2}{*}{6} & Exp & 10001 & 497 & 100 & 50.0 & 30.0 & 0 & 0 & 0 & 20 & 490 \\
\hline & Anal & 9962 & 473 & 91.6 & 54.6 & 22.6 & 3.9 & 3.1 & 2.1 & 23 & 504 \\
\hline \multirow{2}{*}{7} & Exp & 10011 & 501 & 100 & 50.0 & 100 & 19.8 & 9.7 & 0 & 200 & 2520 \\
\hline & Anal & 10303 & 474 & 83.5 & 54.9 & 117 & 17.7 & 11.3 & 1.8 & 187 & 2612 \\
\hline \multirow{2}{*}{8} & Exp & 99892 & 2021 & 1001 & 500 & 602 & 501 & 200 & 100 & 300 & 2300 \\
\hline & Anal & 100321 & 1963 & 963 & 492 & 591 & 513 & 213 & 96 & 315 & 2387 \\
\hline \multirow{2}{*}{9} & Exp & 501020 & 20012 & 4987 & 4993 & 5017 & 4989 & 2998 & 2998 & 5002 & 200020 \\
\hline & Anal & 512120 & 19322 & 4845 & 5076 & 5094 & 4941 & 3082 & 3049 & 4971 & 203512 \\
\hline \multirow{2}{*}{10} & Exp & 45004 & 2000 & 1000 & 500 & 400 & 20.1 & 10.1 & 10.2 & 10.2 & 2200 \\
\hline & Anal & 44841 & 2035 & 1072 & 484 & 431 & 21.6 & 12.3 & 9.67 & 7.1 & 2215 \\
\hline \multirow{2}{*}{11} & Exp & 198972 & 978 & 255 & 302 & 200 & 49.8 & 40.0 & 19.8 & 199 & 700 \\
\hline & Anal & 196742 & 965 & 273 & 316 & 223 & 53.6 & 41.3 & 20.5 & 221 & 694 \\
\hline \multirow{2}{*}{12} & Exp & 198 & 18.1 & 15.0 & 10.0 & 0 & 0 & 0 & 0 & 0 & 504 \\
\hline & Anal & 212 & 15.6 & 18.6 & 16.1 & 5.9 & 2.3 & 4.8 & 0.0 & 2.5 & 513 \\
\hline \multirow{2}{*}{13} & Exp & 502 & 10.1 & 5.0 & 0 & 0 & 0 & 0 & 0 & 0 & 20.2 \\
\hline & Anal & 512 & 7.1 & 0.2 & 0.1 & 5.2 & 0.5 & 4.1 & 3.1 & 0 & 18.3 \\
\hline \multirow{2}{*}{14} & Exp & 39995 & 1987 & 100 & 40.0 & 30.0 & 20.0 & 19.9 & 0 & 400 & 998 \\
\hline & Anal & 40534 & 1836 & 92.4 & 35.2 & 24.8 & 16.3 & 18.6 & 0.1 & 364 & 973 \\
\hline \multirow{2}{*}{15} & Exp & 1989 & 98.2 & 19.0 & 10.0 & 0 & 10.0 & 0 & 5 & 0 & 0 \\
\hline & Anal & 1942 & 95.2 & 15.5 & 10.8 & 3.2 & 12.8 & 0.6 & 3.5 & 6.1 & 0 \\
\hline
\end{tabular}

TABLE 4: Maximum testing error of relative error.

\begin{tabular}{lcc}
\hline Item & Concentration range & Maximum error or relative error \\
\hline 1 & $\leq 10 \times 10^{-6}$ & $9.3 \times 10^{-6}$ \\
2 & $10 \sim 100 \times 10^{-6}$ & $19.9 \times 10^{-6}$ \\
3 & $100 \sim 1000 \times 10^{-6}$ & $9.5 \%$ \\
4 & $1000 \sim 10000 \times 10^{-6}$ & $4.7 \%$ \\
5 & $10000 \sim 100000 \times 10^{-6}$ & $3.5 \%$ \\
6 & $\geq 100000$ & $2.2 \%$ \\
\hline
\end{tabular}

of the close molecular structure between n-butane and npentane, the absorption spectrum of $n$-pentane overlaps with that of $\mathrm{n}$-butane more extensively. Thus the concentration of $n$-pentane was added to that of $n$-butane. If $n$-pentane was taken into account as an interferent and its samples were also prepared, the difference might be reduced greatly. Certainly, in many cases, the total concentration of alkane and the first three components were accounted for, and the difference of the $\mathrm{n}$-butane concentration was not a factor.
Secondly, there was noise in FT-IR, especially for nbutane. It could be evaluated with the adjacent peak-peak value and analysis result:

$$
\begin{aligned}
E_{\text {noise }} & =\frac{\max \left|c_{i}-c_{i+1}\right|}{\left(2 \times \operatorname{mean}\left(c_{i}\right)\right)} \quad i=1,2, \ldots, \\
\operatorname{mean}\left(c_{i}\right) & =\frac{\left(c_{i-3}+c_{i-2}+\cdots+c_{i+3}\right)}{7} \cdots,
\end{aligned}
$$

where $c_{i}$ is the concentration of one component at $i$ th measurement, $E_{\text {noise }}$ denotes the range of noise, and $\max (\cdot)$ means maximization operator. By searching all the results of five components of alkane, it was found that the maximum of $E_{\text {noise }}$ was $6.4 \%$. It appeared in the test results of n-butane at 6:43 A.M. At that time, GC was $280 \times 10^{-6}$ while FT-IR was $290 \times 10^{-6}$. The stabilization of the FT-IR spectrometer was very high. What should be noted was that the maximum errors were chosen at the times when the concentration changes slowly to avoid the effect of the fast change of gas concentration. 


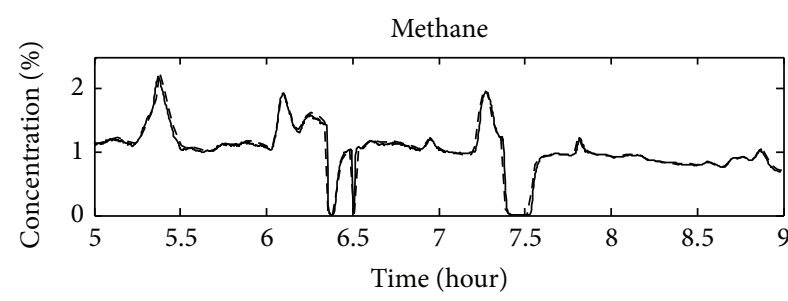

- - GC

- FT-IR

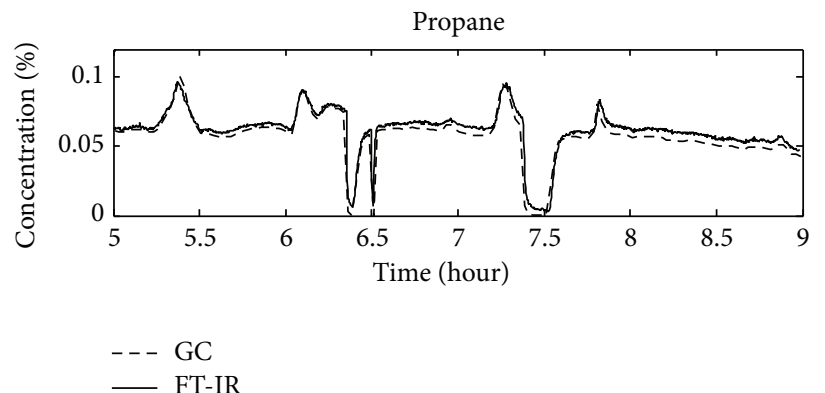

(c)

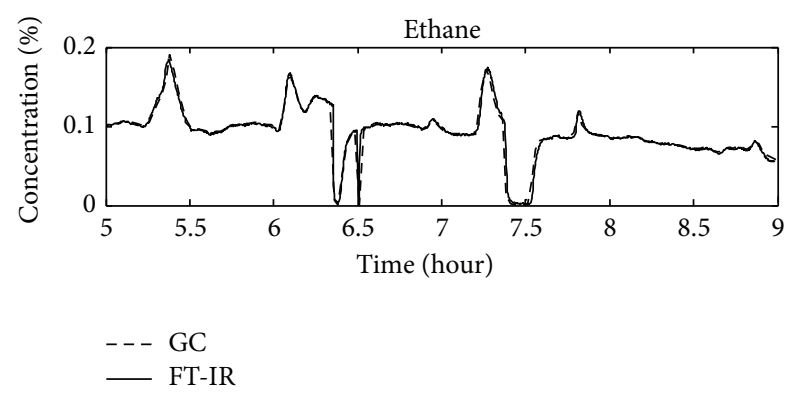

(b)

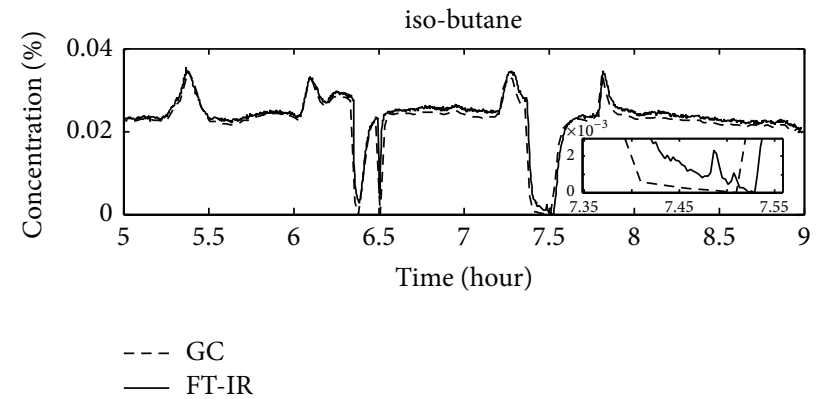

(d)

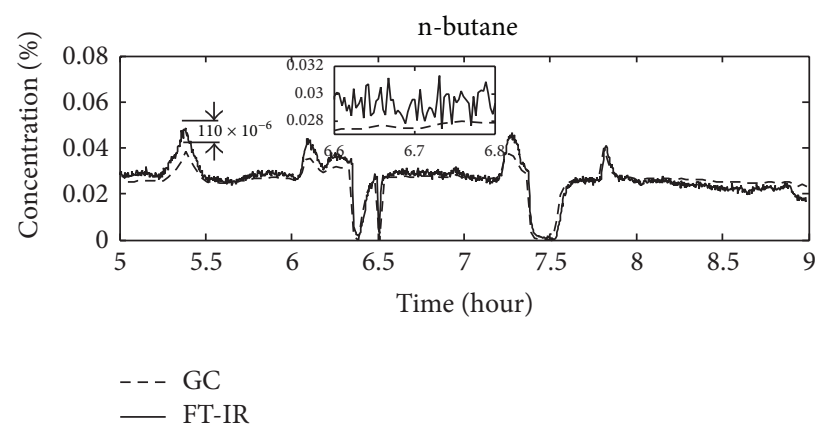

(e)

FIgURE 4: Analysis results obtained with FT-IR spectrometer and with gas chromatograph. (a) Methane, (b) ethane, (c) propane, (d) isobutane, and (e) n-butane.

Third of all, when the GC were all zeroes, for example, as shown in Figure 4(d), in the interval of 7:25 A.M. to 7:32 A.M., FT-IR were not all zeroes but decreasing slowly. This might be due to the gases being diffused into the gaps between sample cell and windows. In almost all FT-IR spectrometers, there is a cavity for placing the sample cell. In order to keep all the elements of Michelson interferometer clean, at two sides of the cavity, there are two windows for keeping the Michelson interferometer isolated from atmosphere. Between the two windows, there is a supporting stage for placing the sample cell. There are two little gaps between the sample cell and the windows. As mentioned in Section 2.3, the FT-IR spectrometer was just placed in petroleum refinery while GC was placed 50 meters away. Because the analyzed gas diffused into the gaps between the gas cell and the spectrum windows, and the cavity was badly ventilated, the concentrations of the analytes in the gaps changed slowly. Even after the concentrations of all the compositions in the gas cell had decreased to zero for several minutes, the concentrations of the gases in the gaps might be still above zero or even at high levels.

\section{Conclusions}

In this paper, both the structure and parameters of the portable gas analyzer based on the FT-IR spectrometer were presented at first. Next, the analysis approach for multicomponent gas mixture was introduced. Finally, the instrument developed in this work was tested with standard gas and tested in situ together with GC. The test results showed that the portable instrument developed with FT-IR spectrometer had the following performance:

(1) This instrument was suitable for patrolling exhaust gas and for monitoring multicomponent gas mixtures including $\mathrm{CH}_{4}, \mathrm{C}_{2} \mathrm{H}_{6}, \mathrm{C}_{3} \mathrm{H}_{8}$, iso- $\mathrm{C}_{4} \mathrm{H}_{10}, \mathrm{n}-\mathrm{C}_{4} \mathrm{H}_{10}$, $\mathrm{C}_{2} \mathrm{H}_{4}, \mathrm{C}_{3} \mathrm{H}_{6}, \mathrm{C}_{2} \mathrm{H}_{2}, \mathrm{CO}_{2}$, and $\mathrm{CO}$;

(2) The detection limit of every component of analyte was less than $10 \times 10^{-6}$;

(3) The maximum noise level was $6.4 \%$ when the practical gas concentration was above $100 \times 10^{-6}$. 
Finally, it could be concluded that the development scheme for the portable gas analyzer was practical. The portable gas analyzer developed in this work could be adopted for use in patrolling and monitoring exhaust gas. Besides oil refineries, there are many other applications. In China, both coalbed methane and coal mine gas [16] are included at least.

\section{Conflict of Interests}

The authors declare no conflict of interests.

\section{Acknowledgments}

The authors are grateful for financial support by National Great Program on Science Instrument Development of China (2012YQ240127) and by National Natural Science Foundation of China (51277144).

\section{References}

[1] B. A. Begum, S. K. Biswas, M. Nasiruddin, A. M. Showkot Hossain, and P. K. Hopke, "Source identification of chittagong aerosol by receptor modeling," Environmental Engineering Science, vol. 26, no. 3, pp. 679-689, 2009.

[2] National Institute of Standards and Technology and United States Department of Commerce, Monitoring, Measurement and Verification of Greenhouse Gas Emissions II: The Role of Federal and Academic Research and Monitoring Programs, 2009.

[3] J. N. Carras, S. J. Day, A. Saghafi, and D. J. Williams, "Greenhouse gas emissions from low-temperature oxidation and spontaneous combustion at open-cut coal mines in Australia," International Journal of Coal Geology, vol. 78, no. 2, pp. 161-168, 2009.

[4] E. Dominguez-Rosado and J. Pichtel, "Phytoremediation of soil contaminated with used motor oil: II. Greenhouse studies," Environmental Engineering Science, vol. 21, no. 2, pp. 169-180, 2004.

[5] A. Adamus, J. Šancer, P. Guřanová, and V. Zubiček, "An investigation of the factors associated with interpretation of mine atmosphere for spontaneous combustion in coal mines," Fuel Processing Technology, vol. 92, no. 3, pp. 663-670, 2011.

[6] B. Pejcic, P. Eadington, and A. Ross, "Environmental monitoring of hydrocarbons: a chemical sensor perspective," Environmental Science \& Technology, vol. 41, no. 18, pp. 6333-6342, 2007.

[7] S.-W. Fei and X.-B. Zhang, "Fault diagnosis of power transformer based on support vector machine with genetic algorithm," Expert Systems with Applications, vol. 36, no. 8, pp. 11352-11357, 2009.

[8] S. Usseglio, K. Thorshaug, A. Karlsson et al., "In situ infrared emission spectroscopy for quantitative gas-phase measurement under high temperature reaction conditions: an analytical method for methane by means of an innovative small-volume flowing cell," Applied Spectroscopy, vol. 64, no. 2, pp. 141-148, 2010.

[9] M. B. Esler, D. W. T. Griffith, S. R. Wilson, and L. P. Steele, "Precision trace gas analysis by FT-IR spectroscopy. 1. Simultaneous analysis of $\mathrm{CO}_{2}, \mathrm{CH}_{4}, \mathrm{~N}_{2} \mathrm{O}$, and $\mathrm{CO}$ in air," Analytical Chemistry, vol. 72, no. 1, pp. 206-215, 2000.

[10] C. J. Thompson, R. G. Riley, J. E. Amonette, and P. L. Gassman, "Quantification of volatile organics in soil aging experiments using fourier transform infrared spectroscopy," Applied Spectroscopy, vol. 60, no. 8, pp. 914-919, 2006.

[11] X. Tang, Y. Liang, H. Dong, Y. Sun, and H. Luo, "Analysis of index gases of coal spontaneous combustion using fourier transform infrared spectrometer," Journal of Spectroscopy, vol. 2014, Article ID 414391, 8 pages, 2014.

[12] P. R. Griffiths and J. A. De Haseth, Fourier Transform Infrared Spectrometry, John Wiley \& Sons, Hoboken, NJ, USA, 2nd edition, 2007.

[13] A. Zhao, X. Tang, W. Li, Z. Zhang, and J. Liu, "The piecewise two points autolinear correlated correction method for fourier transform infrared baseline wander," Spectroscopy Letters, vol. 48, no. 4, pp. 274-279, 2015.

[14] F. Stout, J. H. Kalivas, and K. Héberger, "Wavelength selection for multivariate calibration using Tikhonov regularization," Applied Spectroscopy, vol. 61, no. 1, pp. 85-95, 2007.

[15] H. Yang, P. R. Griffiths, and J. D. Tate, "Comparison of partial least squares regression and multi-layer neural networks for quantification of nonlinear systems and application to gas phase Fourier transform infrared spectra," Analytica Chimica Acta, vol. 489, no. 2, pp. 125-136, 2003.

[16] "Emission standard of coalbed methane/coal mine gas," China, 2008. 

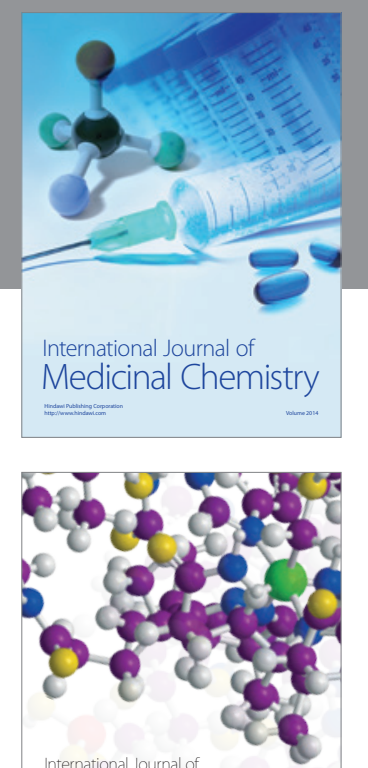

\section{Carbohydrate} Chemistry

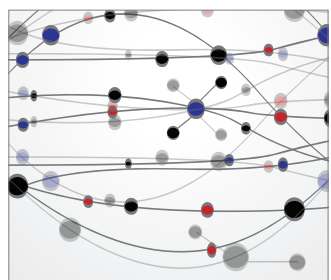

The Scientific World Journal
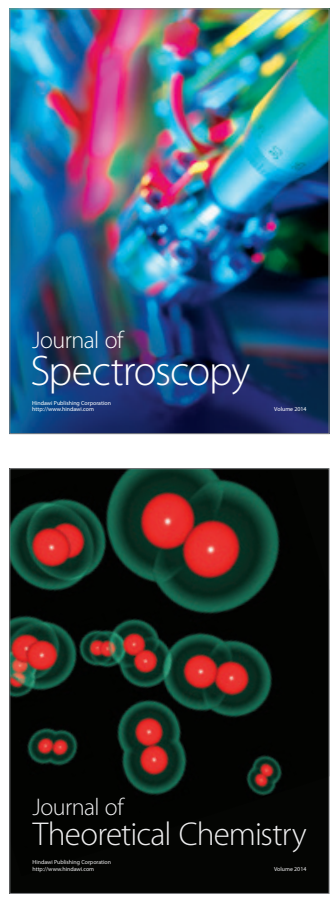
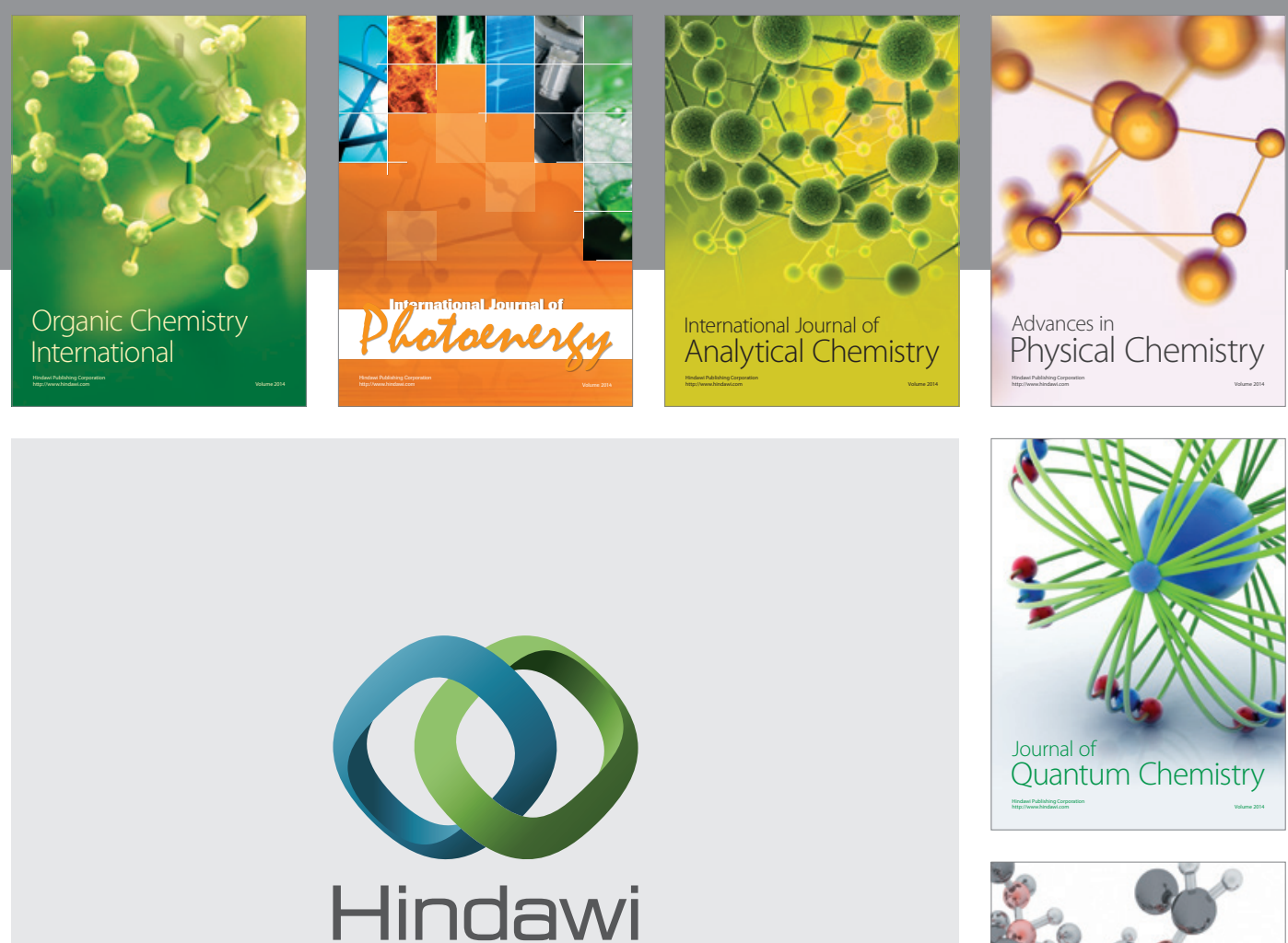

Submit your manuscripts at

http://www.hindawi.com

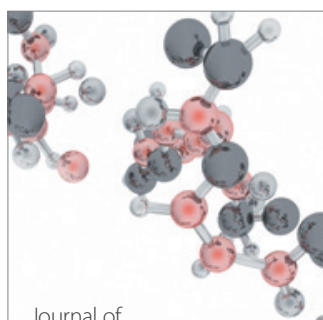

Analytical Methods

in Chemistry

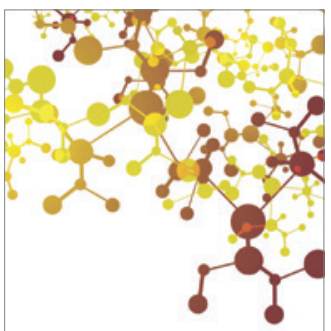

Journal of

Applied Chemistry

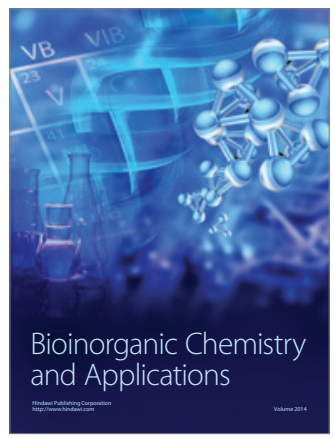

Inorganic Chemistry
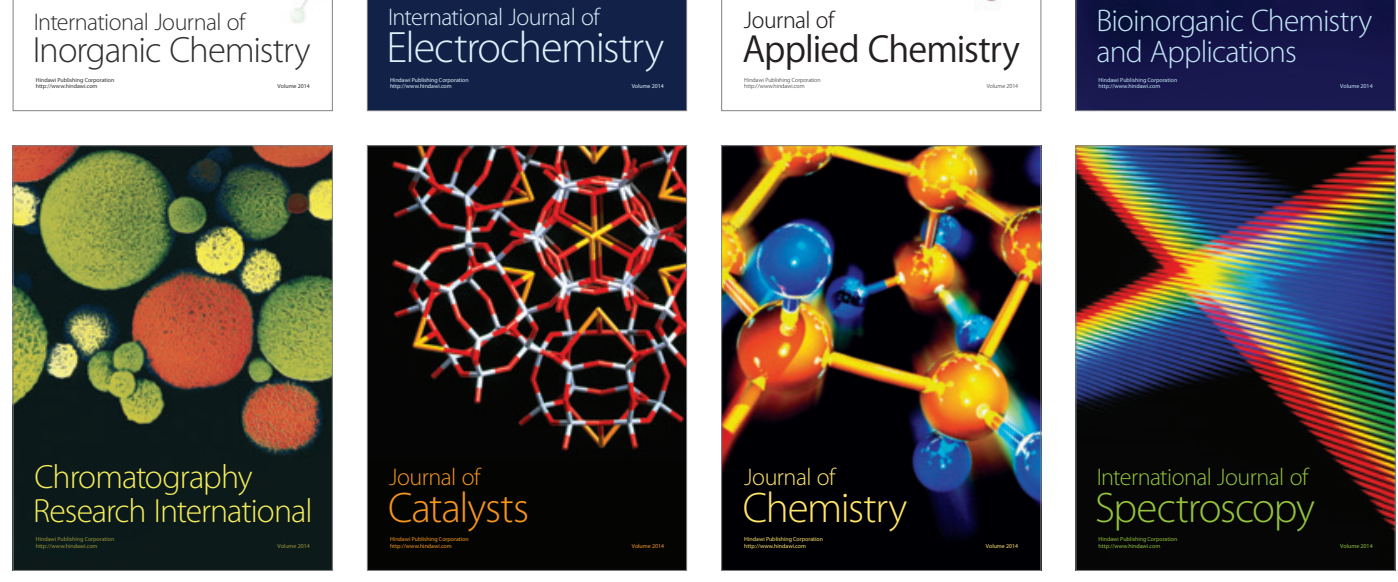